\title{
A Interdisciplinaridade Necessária à Educação Médica
}

\section{The Need for Interdisciplinarity in Medical Education}

PALAVRAS-CHAVE:

- Equipe Interdisciplinar de Saúde;

- Educação Médica;

- Ensino;

- Aprendizagem.

\section{KEY-WORDS:}

- Interdisciplinary Health Team;

- Medical Education;

- Teaching,

- Learning.

Recebido em: 14/07/2006

Reencaminhado em: 06/02/2007

Aprovado em: 02/04/2007

\author{
Maria Alice Amorim Garcia ${ }^{1}$ \\ Anna Thereza B. C e Souza Pinto ${ }^{1}$ \\ Ana Paula de Carvalho Odoni ${ }^{1}$ \\ Bárbara Sugui Longhi ${ }^{1}$ \\ Larissa Iluska Machado ${ }^{1}$ \\ Marina Del Sarto Linek ${ }^{1}$ \\ Natália Amaral Costa ${ }^{1}$
}

\begin{abstract}
RESUMO
Nas Diretrizes Curriculares nacionais, a saúde é considerada uma área interdisciplinar, pois seu objeto "o processo saúde-doença humano "envolve as relações sociais, a biologia e as expressões emocionais. Este estudo analisa os programas e atividades do currículo implantado na Faculdade de Medicina da PUC-Campinas a partir de 2001, no tocante às ações interdisciplinares e multiprofissionais que envolvem os demais cursos da saúde. Procedeu-se à análise documental e de depoimentos de diferentes atores envolvidos no curso. Na perspectiva dos entrevistados, apesar das dificuldades relativas à fragmentação dos saberes e práticas, ao desconhecimento e preconceito acerca dos campos e núcleos das profissões da saúde e à precarização do vínculo docente, tem havido iniciativas de integração, destacando-se os ciclos morfofisiológicos, de correlação clínica e as práticas de Saúde da Família e Comunidade. Concluiu-se que a interdisciplinaridade está presente na proposta curricular e como intenção da Universidade, mas acontece por iniciativas individuais, nas quais se viabilizam "encontros" entre discentes, docentes, funcionários e usuários, que se tornam significativos e demonstram um processo em construção, ainda distante da transdisciplinaridade.
\end{abstract}

ABSTRACT
The National Curricular Guidelines consider health an interdisciplinary area seen that its object
"the process of human health and disease "involves social relations, biology and emotional
expressions. This study aims to analyze the programs and activities of the curriculum implanted
at the Medical School of PUC-Campinas since 2001 with respect to interdisciplinary and multi-
professional actions involving other health courses. Documents and personal statements from
different participants involved in the course were analyzed. From the point of view of the inter-
viewed persons, in spite of some difficulties related to fragmentation of knowledge and practi-
ces, lack of knowledge and prejudice regarding the fields and core areas of the health professi-
ons and the precarious employment conditions of the faculty, integration initiatives have taken
place, above all the morphophysiological cycles, the clinical correlation and the Family and
Community Health practices. We conclude that interdisciplinary is present in the curricular pro-
posal and as an intention of the University, but that it is carried on by individual initiatives, in
"meetings" of students, teachers, employees and patients, winning significance and demonstra-
ting a process in construction but still far away from transdisciplinarity.

${ }^{1}$ Pontífícia Universidade Católica de Campinas, São Paulo, Brasil. 


\section{INTRODUÇÃO}

\section{Árvores de Conhecimentos}

“Cada um descreve suas competências e, a partir de todas as descrições dos membros de uma comunidade, o programa faz uma árvore de todas as competências do grupo. É uma árvore que brota a partir das autodescrições dos indivíduos e não a partir de uma organização a priori do saber. (...) se transforma o tempo todo e cada pessoa tem uma certa distribuição na árvore. Alguns estão um pouco no tronco, um pouco neste galho; outros estão em três galhos diferentes; outros estão todos concentrados...". ${ }^{1}$

Após décadas de críticas e propostas de reformas do ensino médico, surgem novas diretrizes e regulamentações e tornam-se visíveis mudanças na maioria das escolas médicas brasileiras.

Na discussão destas reformas, distinguem-se questões relacionadas ao modelo assistencial, ao modelo tecnocientífico e ao modelo pedagógico. Mudanças que se restringem a um destes níveis são pouco efetivas. São comuns as alterações de grades curriculares, bem como de modelos pedagógicos sem quaisquer fundamentos relativos à ação e à produção do saber em saúde e em educação. A alocação de novas disciplinas ou a introdução de técnicas e instrumentos didáticos não garantem a formação de um profissional competente e compromissado socialmente ${ }^{2-5}$.

Reitera-se a crítica ao isolamento da escola médica que em nome da autonomia universitária produz profissionais, conhecimentos e serviços que não respondem à demanda social. Aponta-se como missão a formação do médico geral ou generalista, mas não se concretizam mudanças estruturais da prática médica, mantendo o direcionamento para as especialidades, o hospital como cenário qualificador dominante e o consultório privado como ideal do trabalho liberal2-6.

Em 1991, foi criada a Comissão Interinstitucional Nacional de Avaliação do Ensino Médico (Cinaem), por 11 entidades ligadas ao ensino e à prática médica no Brasil. Sua proposta contemplava a questão dos recursos humanos, dos médicos formandos e dos modelos pedagógicos e postulava a participação de discentes, docentes, funcionários, entidades médicas e conselhos de saúde num espaço policêntrico e representativo, voltado à realidade de saúde e a partir da qual cada escola construiria criticamente um projeto de ação, ganhando autonomia e capacidade de gestão coletiva ${ }^{3}$.

Nesta mesma década, o Programa UNI propunha: a valorização do ensino-aprendizagem em serviço, possibilitando o exercício competente da profissão nos diferentes níveis do sistema de saúde; a seleção dos conteúdos temáticos com base no perfil epidemiológico; a diversificação dos espaços de ensino-aprendizagem, com atuação multiprofissional; a aplicação de estratégias inovadoras em todo o curso e o incentivo à investigação científica ${ }^{7,8}$.

As sucessivas avaliações das escolas médicas promovidas pelo Ministério da Educação e pela Cinaem evidenciaram resultados insatisfatórios, tais como: currículos arcaicos com carga horária excessiva; falta de articulação teórico-prática e entre os ciclos básico e clínico; despreparo docente; baixa produção de conhecimentos; prática profissional individualizada e impessoal; predomínio da concepção tradicional de ensino baseado na transmissão do conhecimento e na experiência do professor, na supervalorização dos conteúdos e no papel passivo do aluno no processo de aprendizagem 3,9 .

Tais resultados, associados às demandas sociais e da produção científica, passaram a exigir a formulação e o desenvolvimento de novas diretrizes curriculares para os cursos de graduação do País.

Tendo por antecedente e fundamento as experiências do Programa UNI e da Cinaem, entre outras, as diretrizes indicam que as escolas se responsabilizem socialmente pela melhoria da qualidade da saúde e vida das pessoas por meio da transformação da escola e da prática educativa, como também da prática profissional e organização do trabalho. Propõe-se considerar o indivíduo como sujeito de sua aprendizagem, habilitando-o a ultrapassar a esfera da Universidade, estando constantemente atualizado e preocupado com as inovações e com o atendimento integral10,11.

Buscando especificar estas diretrizes, o Ministério da Saúde preconiza o compromisso com a consolidação do SUS e de seus princípios e a responsabilização social e comunicação entre as escolas e a sociedade, tendo por referência a capacidade de dar resposta às necessidades da população, produzindo conhecimentos relevantes para a realidade de saúde, educação permanente dos profissionais e prestação de serviços de boa qualidade $^{12}$.

É nesta perspectiva que se coloca a necessidade da mudança do paradigma biomédico para um modelo baseado na integralidade, ou seja, na ação e produção de conhecimentos que tenham por norte os condicionantes biopsicossocioculturais do processo saúde-doença, visando à formação ético-humanista do profissional e à pessoa em cuidado de modo holístico, enfatizando-se a inter e a transdisciplinaridade ${ }^{12-16}$.

\section{A INTER E A TRANSDISCIPLINARIDADE EM SAÚDE}

Conceituando-se disciplina como campo científico, disciplinaridade seria a exploração científica e especializada de de- 
terminado domínio homogêneo de estudo; conjunto de conhecimentos com características próprias em seus planos de ensino, formação, práticas e matérias. Enquanto exploração, teria por finalidade fazer surgir novos conhecimentos que substituiriam os antigos. Toda ciência é uma disciplina, mas nem toda disciplina é uma ciência ${ }^{13,17}$.

A interdisciplinaridade advém da tradição grega, na qual os programas de ensino eram denominados enkúklios Paidéia e tinham por objetivo a formação da personalidade integral do indivíduo, com acúmulo e justaposição de conhecimentos e a articulação entre as disciplinas formando uma unidade ${ }^{18,19}$.

Porém, com a modernidade, a disciplina passou a ser utilizada como caminho para o conhecimento verdadeiro, levando à desintegração daquela unidade e marcando a consolidação das especializações. A disciplinarização constituída pela racionalidade moderna, fundada no paradigma cartesiano, fragmenta a percepção do humano e, distanciando-se dele, reduz a existência humana a um estatuto de perfeita objetividade ${ }^{14,15}$.

A partir do século 20, especialmente na década de 1970, volta-se a enfatizar a necessidade da interdisciplinaridade em todos os campos científicos. Considerando-se que "todas as ciências são as ciências do humano", apresentam-se diferentes enfoques relacionados à busca de um conhecimento mais amplo, não fragmentado e tendo por desafio o "diálogo e interação das disciplinas, para além das tentativas multidisciplinares que apenas produzem conhecimentos justapostos em torno de um mesmo problema"14.

Segundo Tribarry ${ }^{17}$, uma disciplina sempre depende da interação com outras, e é esta interação que acontece em diferentes níveis. Nos níveis da multidisciplinaridade e pluridisciplinaridade, as relações se dariam num só nível e com múltiplos objetivos, havendo no segundo tipo uma cooperação, mas não coordenação.

Já na interdisciplinaridade, haveria uma axiomática comum e que definiria o grupo de disciplinas conexas num nível hierárquico imediatamente superior, enquanto finalidade, ou seja, seriam coordenadas por princípios e objetivos comuns. Exemplificando pelo trabalho em equipe de saúde, na interdisciplinaridade as ações seriam planejadas em função das necessidades do grupo populacional a ser atendido e não se limitaria às definições apriorísticas de papéis de cada profissional $^{17}$.

De modo esquemático, o que diferenciaria este conceito do de transdisciplinaridade seria a permanência da dominância de determinados saberes. A transdisciplinaridade também envolveria uma coordenação de disciplinas e interdisciplinas sobre uma base axiomática geral, em diferentes níveis e obje- tivos com uma finalidade comum, mas num sistema inovado. Neste sistema, cada disciplina buscaria a compreensão do mundo além de si, numa unidade plural que se caracterizaria como uma estrutura descontínua, que se preocuparia com a dinâmica engendrada em vários e diferentes níveis da realidade ao mesmo tempo ${ }^{17}$.

A inter e a transdisciplinaridade possibilitam pensar problemas não resolvidos por uma área, por meio do diálogo entre áreas e pesquisadores, podendo funcionar como dispositivo que faz avançar relações. Originam-se no trabalho em equipe e no compromisso de gerar dispositivos renovados para a ação, sendo necessário que cada profissional se familiarize com as outras áreas, de modo legitimado e em relações horizontais. Requerem humildade e disponibilidade, num movimento de reconhecimento de dificuldades insolúveis e de posições diferentes em relação a um mesmo objeto ${ }^{17}$.

A transdisciplinaridade faz referência ao holismo e à teoria da complexidade, "total é tudo e não a soma das partes. $\mathrm{O}$ sujeito da prática é o indivíduo, o eixo das interações"20.

A saúde apresenta-se como campo interdisciplinar com alta complexidade, pois requer conhecimentos e práticas de diferentes áreas: ambientais, clínicas, epidemiológicas, comportamentais, sociais e culturais ${ }^{13,14}$.

A inter e a transdisciplinaridade implicam uma consciência dos limites e das potencialidades de cada campo de saber para que possa haver uma abertura em direção de um fazer coletivo, podendo ser uma possibilidade de quebrar a rigidez dos compartimentos em que se encontram isoladas as disciplinas nos currículos ${ }^{14}$.

Esta pesquisa visou analisar as atividades que envolvem o curso de Medicina (med) em ações interdisciplinares e multiprofissionais com as Faculdades de: Enfermagem (enf), Ciências Farmacêuticas (farma), Fisioterapia (fisio), Fonoaudiologia (fono), Nutrição (nutri), Odontologia (odonto), Psicologia (psico) e Terapia Ocupacional (TO).

Buscou-se levantar e descrever estas atividades indicando possíveis campos interdisciplinares e novos cenários para a atuação multiprofissional. Procurou-se também verificar se estas iniciativas seriam condizentes com os propósitos da Universidade e Diretrizes educacionais.

\section{MÉTODOS E TÉCNICAS}

A Faculdade de Medicina e os demais cursos da Universidade inserem-se na rede básica de Campinas, desde o início da década de 1980, inicialmente em unidades próprias, que foram sendo integradas e assumidas pelo município. Acontecem diferentes estágios e disciplinas, principalmente dos últimos anos dos cursos, nas oito unidades do Distrito de Saúde 
Noroeste, no qual se localiza também o Hospital de Ensino, conveniado ao SUS.

Procedeu-se à análise documental e de depoimentos de discentes e dirigentes envolvidos nas reformas das Faculdades do Centro de Ciências da Vida, em especial da Faculdade de Medicina, e representantes das Unidades Básicas de Saúde (UBS).

Foram realizadas entrevistas com 32 alunos, sendo um de cada ano dos cursos (exceto a primeira série), um funcionário de cada UBS (Ipaussurama, Integração, Valença, Pedro de Aquino, Florence e Itajaí) indicado pelo coordenador e os dirigentes ou seus representantes das faculdades de Enfermagem, Fisioterapia, Fonoaudiologia, Medicina, Odontologia e Terapia Ocupacional, totalizando 44 sujeitos entrevistados.

Os indivíduos foram informados sobre os objetivos da pesquisa e a confidencialidade dos dados, assinando o consentimento conforme indicado pelo Comitê de Ética em Pesquisa da PUC-Campinas (protocolo 322/03).

A abordagem dos sujeitos deu-se por meio de entrevistas com roteiro semi-estruturado (questões fechadas e um espaço para observações), cujos itens constam dos resultados.

A entrevista não é um trabalho simples de coleta de dados, mas uma situação de interação, na qual as informações dadas pelos sujeitos podem ser afetadas pela natureza de suas relações institucionais. Toda entrevista, como interação social, está sujeita à mesma dinâmica das relações existentes em nossa sociedade, devendo ser incorporada ao seu contexto ${ }^{21}$.

As propostas derivadas da pesquisa qualitativa pressupõem a existência de diversos pontos de vista e também a inexistência de verdades únicas, universais e eternas. Neste sentido, a visão dos entrevistados passa a ser considerada uma dentre tantas interpretações possíveis ou existentes ${ }^{22}$.

Este material, num total aproximado de 28 horas de gravação, foi transcrito e analisado seguindo a metodologia interpretativa proposta por Minayo ${ }^{21,22}$ : leitura de cada entrevista em seu contexto, como um evento único; "leitura transversal" para a classificação em tópicos e categorias de situações, acontecimentos ou avaliações; revisão das respostas classificadas, analisando-se cada tópico; e finalmente, o estudo de todo o material com base nas referências teóricas e no contexto.

A leitura documental e a análise das entrevistas foram feitas com base nos parâmetros extraídos das diretrizes curriculares para o curso de Medicina e nos referenciais da interdisciplinaridade, destacando-se a explicitação dos conceitos de interdisciplinaridade, suas finalidades e aplicações, cenários de práticas, dificuldades e propostas de superação.

Para salvaguardar o anonimato dos entrevistados, as falas dos alunos foram identificadas pelas siglas do curso (enf, farma, fisio, fono, med, nutri, odonto, psico, TO), e séries no caso da Medicina; as falas dos representantes das faculdades genericamente pela letra " $\mathrm{R}$ ", e as dos funcionários das UBS por UBS.

\section{RESULTADOS E DISCUSSÃO}

\section{A interdisciplinaridade na Faculdade de Medicina da PUC-Campinas}

\section{Como é conceituada?}

A interdisciplinaridade no ensino médico foi abordada segundo as diretrizes do Ministério da Educação ${ }^{10}$, o programa da Faculdade de Medicina da PUC-Campinas ${ }^{23}$ e a perspectiva dos sujeitos.

De acordo com as diretrizes curriculares nacionais: "a saúde é considerada uma área interdisciplinar e esta é colocada como exigência, pois o seu objeto de trabalho - a saúde e a doença - envolve as relações sociais, as expressões emocionais, afetivas e a biologia"10.

Na proposta do novo currículo da Faculdade de Medicina da PUC-Campinas, também se enfatiza a interdisciplinaridade: "priorizar a visão global do ser humano; evitar a visão fragmentada do organismo em doente ou sadio, nos seus aspectos biológico, social e psíquico ou em partes orgânicas isoladas; ensinar o aluno a aprender, buscando a partir de casos motivadores a compreensão global do processo saúdedoença e sua interação social; dar ao aluno a oportunidade de integrar seus conhecimentos desde o início do aprendizado através de uma atitude ativa em relação ao objeto de estudo; estimular as discussões interdisciplinares; inserir precocemente o aluno na comunidade"23.

Quanto à visão dos sujeitos entrevistados, observou-se a aplicação do conceito de interdisciplinaridade referido por Tribarry ${ }^{17}$, entendendo-se que se deveria ultrapassar a soma de disciplinas: “a união e a cooperação entre diversas áreas do saber e do conhecimento que têm um objetivo em comum e querem melhorar e lutar por esse objetivo" $\left(2^{\circ} \mathrm{med}\right)$.

\section{A que se aplica?}

Segundo os discentes, a interdisciplinaridade é uma exigência da sociedade para a medicina atual, a qual deve integrar a atuação individual e coletiva, a prevenção e a cura, e os conhecimentos da clínica e da epidemiologia: "atualmente se preza o médico que observa o paciente como um todo biopsicossocial" ( $2^{\circ}$ med).

Tal integração, construída com base em objetivos comuns, possibilitaria ampliar perspectivas de atuação: "nos fará médi- 
cos muito melhores porque você vai levantar várias possibilidades, permitindo chegar a vários diagnósticos, levantando futuras modificações e alertas pertinentes ao paciente, ou seja, atuando preventivamente, abrindo horizontes, promovendo a cura e a melhora do estado de saúde do paciente" ( $2^{\mathrm{o}}$ med).

Possibilitaria, também, o cumprimento das competências e habilidades preconizadas nas Diretrizes Curriculares Nacionais do Curso de Graduação em Medicina, que são: atenção à saúde (promoção, prevenção, proteção e reabilitação da saúde tanto individual como coletivamente), tomada de decisões, comunicação, liderança (tendo em vista o bem-estar da comunidade e envolvendo compromisso, responsabilidade, empatia, habilidade), administração e gerenciamento, educação permanente e conhecimentos, competências e habilidades específicas, sempre buscando uma visão holística do paciente ${ }^{11}$.

Permitiria, assim, uma aproximação à integralidade ${ }^{16}$, propiciando mudanças na produção de saberes e na formação profissional: "a integração entre os cursos é importante para a construção da ciência, para a produção de um conhecimento mais completo, menos segmentado (...) não podemos através de uma ciência única ser capaz de abranger todas as necessidades das pessoas, da sociedade" (5 $\left.5^{\circ} \mathrm{med}\right)$, concordando com o que foi proposto pelas Diretrizes do novo currículo da Faculdade de Medicina ${ }^{23}$.

Nesta perspectiva, foi salientada a importância da interdisciplinaridade no processo de humanização do cuidado em saúde 2: "é essencial para a formação do estudante como profissional e pessoa" ( $2^{\circ}$ med). E mais especificamente na melhoria da resolutividade e na reordenação dos diversos níveis do sistema: "O retorno é superpositivo, o caso recebe uma solução mais adequada. Conseguimos detectar casos mais graves e encaminhá-los. Só que a integralidade e essa co-responsabilidade dependem também dos demais níveis de atenção. O Sistema precisa trabalhar como a engrenagem de um relógio, tudo se encaixando" (UBS).

\section{Apresenta-se como proposta curricular?}

Observou-se que a interdisciplinaridade se apresenta como proposta da Faculdade de Medicina ${ }^{23}$, enquanto integração de disciplinas "médicas" e, com menor ênfase, enquanto integração com os demais cursos da área da saúde (multiprofissionalidade): "no novo currículo procurou-se modificar a orientação pedagógica para a inserção precoce do aluno na comunidade, o desenvolvimento do raciocínio clínico e crítico, a busca de informações (...) a autonomia no aprendizado e uma aplicabilidade imediata do mesmo" (R).

Entretanto, parte das iniciativas relatadas pelos atores não se encontra registrada formalmente no programa 23 : "a inter- disciplinaridade é desenvolvida em todos os anos por meio de uma metodologia que permite levar todas as disciplinas a um desenvolvimento simultâneo e integrado com discussões e atividades pedagógicas em conjunto" (R).

Em relação à atuação multiprofissional, os dirigentes das faculdades de Fisioterapia, Fonoaudiologia, Terapia Ocupacional, Odontologia e Enfermagem afirmaram que as atividades integradas aconteciam anteriormente às reformas curriculares.

\section{Como e onde ocorre?}

\section{No planejamento pedagógico}

Enfatizou-se o processo cotidiano de planejamento pedagógico e o trabalho em equipe como estratégia para a interdisciplinaridade, mesmo com as dificuldades da estrutura da Universidade no que concerne à contratação de docentes horistas: "a proposta de juntar vários indivíduos de diferentes áreas e fazer conversar já é muito difícil, mas se conseguiu aqui na PUC e eu até me assustei como funcionou bem (...) No dia-a-dia, os docentes conversam um com o outro, sabem das dificuldades dos outros, sabem se a aula teve retorno. Antes, o aluno poderia estar estudando proteína na bioquímica, metabolismo de gordura na fisiologia e depois estaria falando na anatomia de cérebro e na histologia de fígado. Era totalmente desarticulado, e é essa integração que se trabalha no planejamento" (R).

A capacitação e a educação permanente do docente visam diminuir as resistências e preparar para o processo de ensinoaprendizagem: "essa integração antes de chegar ao aluno é muito importante, pois não adianta propor um currículo integrado se os professores não quiserem (...) um dos objetivos é o de que as pessoas aprendam a trabalhar em equipe" (R).

\section{$\mathrm{Na}$ articulação entre disciplinas}

No primeiro ciclo do curso, busca-se integrar conhecimentos clínicos e morfofisiológicos: "há um eixo do conhecimento que desenvolve as disciplinas básicas, as correlações clínicas e a inserção precoce na comunidade" (R).

Como relatado por um discente, por meio de casos motivadores a clínica conduz a formação: "você consegue palpar, ver o que está alterado, saber as funções e o que vai mudar na vida daquele paciente, as conseqüências, o que fazer para ajudar e para formar um raciocínio clínico pensando em tudo (...) usamos a anatomia, fisiologia, histologia, a medicina social, para estudar os problemas daquela pessoa" ( $\left.3^{\circ} \mathrm{med}\right)$.

A partir dos núcleos de conhecimentos e práticas da Saúde Coletiva e da Clínica, procura-se constituir campos de cuida- 
do: "no $1^{\text {o }}$ ano tivemos contato com a comunidade, com as famílias e outros profissionais (...) Ao observar a situação social, é possível compreender quais comportamentos propiciam ou não aquela doença" ( $\left.4^{\circ} \mathrm{med}\right)$.

Já no ciclo que antecede o internato, a construção de pontes é mais difícil: "a partir do terceiro ano, já existe uma separação maior, que é a Pediatria, separada da Obstetrícia, que é separada da Clínica, mas dentro de cada área eles se reúnem para discutir em conjunto e definir o papel de cada um, havendo certa simultaneidade no conteúdo e na forma de avaliar. Ao analisar as avaliações, percebem-se problemas, mas essa integração tem permitido que as áreas caminhem juntas, numa seqüência mais clara para o aluno" (R).

Quanto ao internato, em processo de implantação, buscase que "cada estágio integre todos os participantes, com base nos objetivos terminais do curso (...) havendo uma integração vertical, onde o segundo ano sabe o que o primeiro fez, o terceiro sabe do segundo, e assim por diante... o internato tendo noção de como o aluno está chegando" (R).

Como discutido por Feuerwerker" ${ }^{9}$, nem tudo o que se propõe e se vislumbra acontece nas reformas curriculares, pois há inúmeras dificuldades, como as indicadas abaixo.

\section{Nos cenários de práticas}

Foram citados como momentos privilegiados os espaços relacionados à atenção básica: "no nível da atenção primária, a demanda chega sem nenhum trabalho, 'pura', e nenhum profissional sozinho consegue dar conta de tamanha complexidade (...) a ocorrência de um trabalho conjunto faz com que as diversas áreas se orientem (...) ajuda o doente, pois cada profissional tem uma visão diferente" (UBS).

Destacaram as atividades multiprofissionais no estágio de Atenção à Família: "no programa Paidéia de Saúde da Família, entram os profissionais da medicina, enfermagem, dentista, psicólogo, nutricionista, fisioterapeuta e o agente de saúde, que é fundamental (...) temos as visitas domiciliares, as reuniões das equipes de saúde; os grupos de hipertensos e diabéticos" (UBS).

O espaço hospitalar também foi citado, mas a integração entre os profissionais deixa a desejar: "no hospital da PUC, ocorre pouca integração. Eu, enquanto direção, gostaria que ocorresse mais" (R). Demonstrou-se a ocorrência da multidisciplinaridade, estando os profissionais inseridos em um esquema automático que não gera espaço para articulações ${ }^{17}$.

\section{Em atividades complementares}

O fomento pela Universidade de atividades complementares visa à constituição de espaços de integração, tendo sido apon- tadas as Práticas de Formação (atividades curriculares eletivas), a Saúde na Praça, a Semana de Amamentação, as Ligas: "na saúde na praça, participa a medicina, odonto, farmácia, nutrição (...) e agora tem a Liga do Trauma. Através de ligas, pode-se envolver vários cursos" (odonto); "as práticas de formação facilitam um entendimento mais global da Universidade, como práticas filosóficas, culturais, religiosas, sociais" (5o $\mathrm{med}$ ).

\section{Há dificuldades? Quais são?}

A fala de muitos alunos explicitou a competição entre profissionais e o desconhecimento do papel de cada um: "a gente olha os outros cursos com preconceito, mas acho que está mudando" ( $2^{\circ}$ med); "dizem que é difícil chegar aos alunos da medicina, perguntar alguma coisa, mas na minha experiência eu sempre fui auxiliada por eles. Acho que há um tabu da medicina ser difícil de lidar" (enf).

Apontou-se a "dominância" do saber biomédico, incorporado principalmente pelo profissional médico, mas não somente por este, pois se abordam as relações profissionais utilizando-se o termo "auxiliar", que demonstra a existência de hierarquias, distantes da interdisciplinaridade.

Depara-se com relações de poder e prepotência: "um não respeita o outro, acha que sabe mais que o outro" (enf); "muitas pessoas acreditam que o que elas sabem é sempre mais importante e acabam sendo egoístas ou prepotentes e levando ao desrespeito. É preciso uma certa humildade para que as pessoas possam conviver num mesmo espaço" (5oㅡㄹ $\mathrm{med}$ ).

Falta esta "humildade" descrita pelo aluno, que poderia ser traduzida como uma abertura para a dúvida, para a busca de conhecimento, como também clareza (e interesse) quanto aos núcleos de saber de cada profissional e os possíveis campos de intersecção ${ }^{13,14,17: ~ " a l g u n s ~ p r o f i s s i o n a i s ~ a c a b a m ~ u l t r a-~}$ passando barreiras e invadindo a área do outro" (fono).

Muitos espaços não são aproveitados por falta de iniciativa dos docentes e orientação dos cursos: "mesmo passando por estágio na mesma enfermaria do hospital, ainda não há integração com a medicina. Falta conscientização de muitos alunos e professores" (enf).

Estas questões ilustram a dificuldade para o trabalho em equipe, para o qual é necessário que cada profissional se familiarize com as outras áreas ${ }^{17}$.

Assim, boa parte das diretrizes explicitadas pelos dirigentes limita-se a iniciativas individuais ou de pequenos grupos: "há professores que estimulam, outros que se contentam mais com aquela informação que têm, mas eu acho que de maneira geral tem um estimulo da faculdade" ( $\left.3^{\mathrm{o}} \mathrm{med}\right)$.

Segundo os dirigentes, há dificuldades estruturais, como a contratação dos docentes como horistas: "cada docente re- 
cebe só para a sua disciplina e é difícil promover encontros" (R).

Os docentes apresentam limitações decorrentes de sua formação nos moldes disciplinares: "em parte deles essa falta de incentivo provém de sua própria formação. (...) Nem sempre os professores estão abertos a novas propostas" (R).

Também nas UBS há dificuldades de encontro que se "relacionam com a grade horária dos alunos, que impede que estejam no Centro de Saúde na hora das atividades" e a "falta de diálogo entre os colegas" (R).

De todos estes itens, entretanto, o principal entrave pareceu dever-se ao "enraizamento" do modelo biomédico, que marca, inclusive, as exigências da população: "os usuários às vezes rejeitam a multiprofissionalidade, pois consideram que somente o médico é quem resolve seus problemas" (UBS).

\section{O que sugere?}

Conforme referiram, ainda há muito a construir no caminho da inter e transdisciplinaridade, observando-se que deveria haver estratégias e ações diversificadas, envolvendo os diferentes sujeitos e cenários: "estamos no caminho certo, mas parece que está um pouco bagunçado (...) os alunos começam o curso muito perdidos e só se situam com o tempo para saber o que e como estudar, onde procurar, como integrar (...) falta apoio maior nesse $1^{\circ}$ ano" ( $\left.4^{\mathrm{o}} \mathrm{med}\right)$.

Para alguns, os alunos deveriam ser o foco principal: "como é difícil mudar o professor, tem que trabalhar principalmente com o aluno, incentivar para que busque vários pontos de vista, várias fontes para entender um objeto" ( $2^{\mathrm{o}}$ med).

A antecipação das atividades práticas em contato com usuários propicia a vivência do cotidiano do trabalho, comportando-se como estratégia pedagógica privilegiada: "a gente tem o contato mais cedo com o paciente e assim ajuda a desenvolver a inter-relação de vários conhecimentos" $\left(2^{\circ} \mathrm{med}\right)$.

O papel da Universidade seria estimular iniciativas que resultam positivamente: "trabalhar com os professores que realizam interações" ( $3^{\text {o }}$ med); "implantar o Hospital Amigo da Criança, pois permite que se envolva todo mundo, desde o rapaz da limpeza até o médico especialista" ( $\left.5^{\circ} \mathrm{med}\right)$.

Observou-se a inadequação da infra-estrutura física dos cenários de práticas: "há necessidade de melhorar a estrutura física. Mesmo no hospital, freqüentemente faltam salas" ( $3^{\circ}$ med).

Mas o fundamental seria desenvolver "uma cultura" interdisciplinar13,15,17: "na prática, é questão de desenvolver uma cultura e, a partir do momento em que as coisas começarem a acontecer, em um futuro próximo esta integração poderá ser maior do que é hoje" (R).
Na saúde, esta cultura pode e deve ser implementada junto ao SUS, conforme indicado pelas diretrizes curriculares 12,16: “a inserção no SUS traz por meta a integralidade. Quando se está trabalhando com uma doença, muitas vezes se esquece que aquela pessoa tem uma vida (...) há um momento em que se estuda ética, mas ninguém mais fala disso; fala-se em perfil psicológico somente na psicologia médica. É preciso trabalhar com os professores para que tenham essa visão que extrapola a questão pedagógica" (R).

\section{CONCLUSÃO}

Nas diretrizes curriculares nacionais para os cursos da saúde, a interdisciplinaridade é apontada como fundamental para a abordagem integral do processo saúde-doença, sendo concebida como integração de disciplinas, de áreas de conhecimentos ou de profissionais, podendo facilitaroendo ntes cursos e enfoques, ursos da saal m[endizagem o aprendizado, a organização do trabalho e a comunicação entre os diferentes cursos, direcionando para a configuração transdisciplinar, na qual nenhum saber prevaleceria sobre o outro6,10,11.

Os processos de mudanças curriculares são complexos, demorados e envolvem questões estruturais das Universidades e dos serviços, como a forma de contratação dos profissionais, que dificulta o vínculo com as equipes e usuários; a integração docente-assistencial precária na maioria dos cenários; a tradição do modelo biomédico e, inclusive, as resistências às mudanças por parte dos gestores, docentes e dos próprios discentes ${ }^{9,12}$.

Embasado nas diretrizes nacionais, nas propostas da $\mathrm{Ci}$ naem e em movimentos nacionais e internacionais, o currículo analisado faz parte de um processo de mudanças das escolas médicas para uma formação humanizada, ética e que prioriza a busca da autonomia na aprendizagem $3,10-12$.

Foram constatadas diversas atividades compreendidas como multiprofissionais e tendendo à interdisciplinaridade, nas UBS e no Hospital Universitário. Os "encontros" entre alunos, professores e funcionários foram os mais significativos e marcam a possibilidade de aproximação da inter e transdisciplinaridade.

É importante destacar que algumas destas atividades precedem a reforma curricular implantada em 2001 na Faculdade de Medicina da PUC-Campinas. Já na década de 1980 se enfatizava a integração docente-assistencial e a inserção da Faculdade no sistema público, com ênfase na Atenção Básica e Saúde da Família. Evidencia-se que, mesmo se tratando de uma Universidade particular, pode-se e deve-se responder as diretrizes do SUS 8,23 .

O fato de a UBS ter sido apontada como um espaço privilegiado da multiprofissionalidade decorre da inserção históri- 
ca da equipe docente da Saúde Coletiva nesse nível de atenção, que exige a atuação em equipe, a responsabilização e vínculo com os usuários ${ }^{8,23}$.

Outro espaço privilegiado de integração descrito pelos entrevistados refere-se às disciplinas dos primeiros anos que contam com o investimento da Universidade na formação e educação permanente dos docentes para o desenvolvimento da abordagem pedagógica baseada na problematização e integração das áreas morfofisiológicas, clínicas e da saúde coletiva.

Foram descritas situações que marcaram os entrevistados, evidenciando-se que há espaço para a interdisciplinaridade. Há cooperação, mas falta coordenação das disciplinas com vistas ao cumprimento de finalidades afins, no sentido da integralidade.

Observou-se que o encontro construtivo não é garantido pela vivência de um cenário comum e que a preocupação com a interdisciplinaridade está centrada em alguns docentes e profissionais. Considerando que muitas atividades ocorrem por iniciativas individuais, o que aconteceria se essas pessoas deixassem estes cenários?

Fica também como questionamento a não utilização plena do hospital universitário como espaço de integração, mesmo tratando-se de cenário de práticas dos diferentes cursos da área da saúde. A centralidade do modelo biomédico dificulta a aproximação, mantendo-se a perspectiva de "auxílio" entre os profissionais e a referência ao "preconceito" e à "arrogância".

Seria interessante avaliar a perspectiva dos docentes na qualidade de atores deste processo.

Conclui-se que a interdisciplinaridade é uma exigência para a integralidade e se apresenta como uma preocupação do curso de Medicina, principalmente no planejamento pedagógico, na articulação entre as disciplinas, nos cenários de práticas e em atividades complementares.

As experiências relatadas demonstram que há muito a caminhar, mas o terreno é propício: não se constitui somente de intenções, mas de gestos e atos consolidados, e outros abertos a traçar novos caminhos.

\section{REFERÊNCIAS}

1. Lévy P. Árvores de Saúde. Interface. 1999; 3(4):143-56.

2. Chaves MM. Educação das profissões da saúde: perspectiva para o século XXI. Rev Bras Educ Med. 1996; 20(1): 2187.

3. Comissão Interinstitucional Nacional de Avaliação do Ensino Médico. Preparando a transformação da educação mé- dica brasileira: projeto CINAEM III fase: relatório 19992000. Pelotas: UFPel; 2000. [mimeo].

4. Schraiber LB. Educação médica e capitalismo: um estudo das relações educação e prática médica na ordem social capitalista. São Paulo: Hucitec; 1989.

5. Sobral DT. Retrospecto da cúpula de Edimburgo: subsídios para a educação médica. Rev Bras Educ Med. 1994; 18(3): 103-10.

6. Padilha RQ. PROMED: Programa de Incentivo a Mudanças Curriculares nas Escolas Médicas. In: Brasil. Ministério da Saúde. Organização Pan-Americana da Saúde. Organização Mundial da Saúde. Política de recursos humanos em saúde: seminário internacional. Brasília: MS; 2002. p.15661.

7. Marsiglia RG. Relação ensino/serviços: dez anos de Integração Docente-Assistencial (IDA) no Brasil. São Paulo: Hucitec; 1995.

8. Garcia MAA, Pachioni AM, Domingues P. O aluno de medicina em serviços docente-assistenciais da rede básica. Rev Bras Educ Med. 1998; 22(2-3): 48-57.

9. Feuerwerker LCM. Além do discurso de mudança na educação médica: processos e resultados. São Paulo: Hucitec; 2002.

10. Brasil. Ministério da Educação e do Desporto. Secretaria de Educação Superior. Edital n.4/97. [Dispõe sobre propostas para diretrizes curriculares dos cursos superiores]. Brasília: MEC; 1997.

11. Brasil. Ministério da Educação. Conselho Nacional de Educação. Câmara de Educação Superior. Resolução n.4, CNE/ CES de 7/11/2001. Institui diretrizes curriculares nacionais do curso de graduação em medicina. Brasília: MEC; 2001.

12. Brasil. Ministério da Saúde. Secretaria de Gestão do Trabalho e da Educação na saúde. Departamento de gestão da Educação na Saúde. Caminhos para a mudança da formação e desenvolvimento dos profissionais da saúde: diretrizes para a ação política para assegurar Educação Permanente no SUS. Brasília: MS; 2003.

13. Minayo MCS. Interdisciplinaridade: uma questão que atravessa o saber, o poder e o mundo vivido. Med Ribeirao Preto. 1991; 24(2): 70-7.

14. Gomes R, Deslandes SF. Interdisciplinaridade na saúde pública: um campo em construção. Rev Lat Am Enfermagem. 1994; 2(2): 103-14.

15. Almeida Filho N. Transdisciplinaridade e saúde coletiva. Cienc Saude Coletiva. 1997; 2 (1-2): 5-20. 
16. Mattos RA. Os Sentidos da Integralidade: algumas reflexões acerca de valores que merecem ser defendidos. In: Pinheiro R, Mattos RA. Os sentidos da integralidade na atenção e no cuidado à saúde. São Paulo: Hucitec; 2001.

17. Tribarry IN. Aproximações sobre a transdisciplinaridade: algumas linhas históricas, fundamentos e princípios aplicados ao trabalho de equipe. Psicol Refl Crit. 2003; 16(3): 483-90.

18. Nunes ED. Interdisciplinaridade: conjugar saberes. Saude Debate. 2002; 26(62): 249-58.

19. Vilela EM, Mendes IJM. Interdisciplinaridade e saúde: estudo bibliográfico. Rev Lat Am Enfermagem. 2003; 11(4): 525-31.

20. Pires MFC. Multidisciplinaridade, interdisciplinaridade e transdisciplinaridade no ensino. Interface. 1998; 2(2): 17382.

21. Minayo MCS. O desafio de conhecimento: pesquisa qualitativa em serviço. 2 ed. São Paulo: Hucitec; 1993.
22. Bosi MLM, Mercado FJ, orgs. Pesquisa qualitativa de serviços de saúde. Petrópolis: Vozes; 2004.

23. Pontifícia Universidade Católica de Campinas. Projeto pedagógico da Faculdade de Medicina. [Campinas: PUC-Campinas]; 2001. [mimeo].

\section{Conflito de Interesse}

Declarou não haver.

\section{Endereço para correspondência}

Maria Alice Amorim Garcia

Faculdade de Medicina - Pontifícia Universidade Católica de Campinas, campus II

Av John Boyd Dunlop, s/no - Jardim Ipaussurama 13059-900 - Campinas - SP

e-mail: malicegarcia@puc-campinas.edu.br 